(c) American Dairy Science Association, 2003.

\title{
Factors Affecting Stall Use for Different Freestall Bases
}

\author{
A. M. Wagner-Storch, ${ }^{\star}$ R. W. Palmer, ${ }^{\star}$ and D. W. Kammel, $\dagger$ \\ University of Wisconsin, Madison 53706 \\ *Department of Dairy Science \\ †Biological Systems Engineering Department
}

\begin{abstract}
The objective of this study was to compare stall use (stall occupancy and cow position) by barn side for factors affecting stall use. A closed circuit television system recorded stall use four times per day for a 9-mo period starting May 9, 2001. Six factors were analyzed: stall base, distance to water, stall location within stall base section, stall location within barn, inside barn temperature, and length of time cows were exposed to stall bases. Two barn sides with different stocking densities were analyzed: low (66\%), with cows milked by robotic milker; and high (100\%), with cows milked $2 \mathrm{X}$ in parlor. Six stall base types were tested: two mattresses, a waterbed, a rubber mat, concrete, and sand (high side only). The base types were grouped 3 to 7 stalls/section and randomly placed in each row. Cows spent more time in mattress-based stalls, but the highest percentage lying was in sand-based stalls. The following significant stall occupancy percentages were found: sand had the highest percentage of cows lying on the high stocking density side (69\%), followed by mattress type $1(65 \%)>$ mattress type $2(57 \%)>$ waterbed $(45 \%)>$ rubber mat $(33 \%)>$ concrete $(23 \%)$. Mattress type 1 had the highest percentage stalls occupied (88\%), followed by mattress type $2(84 \%)>$ sand $(79 \%)>$ soft rubber mat $(65 \%)>$ waterbed $(62 \%)>$ concrete $(39 \%)$. On the low stocking rate side, mattress type 1 had the highest percentage cows lying $(45 \%)$ and occupied (59.6\%), followed by mattress type $2>$ waterbed $>$ soft rubber mat $>$ concrete. Cow lying and stalls occupied percentages were highest for stalls 1 ) not at the end of a section, and 2) on the outside row, and varied by base type for time cows exposed to stalls and inside barn temperature. Lying and occupied percentages were different for different mattress types. The percentage of stalls with cows standing was higher for mat and mattress-based stalls. Results show mattress type 1 and sand to be
\end{abstract}

Received May 14, 2002.

Accepted December 4, 2002.

Corresponding author: Roger W. Palmer; e-mail: rwpalmer@ facstaff.wisc.edu. superior and rubber mats and concrete inferior stall bases.

(Key words: stall use, cow preference, stocking density, freestall base)

Abbreviation key: 100\%SD = higher stocking density, END = stalls on row ends or next to a different stall base, NOTEND = stalls not on row ends or next to different stall bases, LowSD = low stocking density, MATR1 $=$ mattress type 1, MATR2 $=$ mattress type 2, RH\% = relative humidity, $\mathbf{R L O C}=$ barn side, STLLOC $=$ stall location within stall base section, WDIST $=$ distance to water, XPOSR = length of time cows exposed to stall bases.

\section{INTRODUCTION}

Cow comfort is an important component of production and overall health. Stall use can be an indicator of cow preference, and preference can be interpreted as a measure of cow comfort. Improving cow comfort can affect a cow's milk yield and productive life, and the overall success of a dairy operation.

Monitoring stall use percentages provides an indication of cow preference and comfort level. Videotape images and time-lapse photography have been used to observe stall use and cow activity, lying or standing in stalls, or feeding (Albright and Timmons, 1984; Krohn and Munksgaard, 1993; Herlin, 1997; Haley et al., 1999; Overton et al., 2000). Observing cow activity through videotape images versus on-site removes the potential influence of human presence on cow activity.

Stall base and design influence cow acceptance and comfort. Stalls providing a comfortable, conforming base, and designed to allow for ease of rising and lying movements are used more by the cows (Bickert and Ashley, 1991). Incorrect stall design inhibited stall use (Feddes et al., 1995; Muller and Botha, 1997). Thickness or depth of the stall base, 3 to 6 in (7.6 to $15.2 \mathrm{~cm}$ ) for mattresses, improved durability and cow comfort (Bickert and Ashely, 1991; House, 1998).

Stall usage research has been reported for cows exposed to sand, mattress, and rubber-mat based stalls. Sand was considered the best in providing comfort (Tucker and Weary, 2001). Because sand settles and 
separates from manure, it requires a specially designed manure management system (Bickert and Ashley, 1991; Leonard and O'Connell, 1997; Thoreson et al., 2000). Rodenburg and House (2000) review of previous research found lying percentages were higher on rubber-filled mattress stalls (43.3\%) versus sand stalls (26.4\%).

House et al. (1994) and Chaplin et al. (2000) found rubber-filled mattresses had a higher frequency of use than rubber-mat bases. However, conflicting results were reported by Rodenburg et al. (1994), who found average lying percentage to be higher on rubber mats versus rubber-filled mattresses.

Length of time cows are exposed to particular stall bases influences lying and occupancy percentages. Cows exposed to rubber mats had a longer adjustment period than those exposed to mattresses (Chaplin et al., 2000). Occupancy of waterbed-based stalls started low, but increased with time as cows became accustomed to them (Sonck and Daelemans, 1999; Rodenburg and House, 2000). Occupancy rates on waterbeds were lower initially, but were the same as rubber-filled mattresses at the end of the trial (Sonck and Daelemans, 1999).

Temperature may play a role in cow preference for a particular stall. Earth with deep bedding, and rubbermat-based stalls were chosen over carpet and concretebased stalls during summer and winter trials (Gebremedhin et al., 1981). Thoreson et al. (2000) found sand (60.8\% occupancy) was favored over mattresses (19.4 to $32.5 \%$ occupancy) and rubber mats (12.3\% occupancy) during a summer trial. Sand stalls were found to be used (occupied) less during winter (27\%) compared to summer (60.8\%) (Thoreson et al., 2000).

Natzke et al. (1982) found stall use was less for stalls on the interior row of the barn and for stalls located on the ends of the exterior and interior rows of the barn. However, Sonck and Daelemans (1999) found stall base position and location in the barn did not affect occupancy level. Conflicting reports show no consistent effect of stall location on stall use.

Increased stocking density (number of cows per stall multiplied by 100) above $100 \%$ may not result in a loss of cow comfort or stall use. Maximum stall use for a $100 \%$ stocked freestall barn was $86 \%$, suggesting stocking density of 110 to $115 \%$ should not affect stall availability (Gebremedhin et al., 1981). House et al. (1994) reported $95 \%$ lying in a freestall barn with mattress bases and a 58 to $69 \%$ stocking density.

Previous studies have shown stall base, design, location, length of exposure time, temperature, and stocking density influence stall use. Different stall bases have been evaluated with conflicting stall usage results. The objective of this study was to compare stall occu- pancy and cow position (lying in or occupying stall) for six factors affecting stall use: stall base, distance to water (WDIST), stall location within stall base section (STLLOC), barn side (RLOC), inside barn temperature, and length of time cows exposed to stall bases (XPOSR).

\section{MATERIALS AND METHODS}

The study was conducted in the University of Wisconsin-Madison Arlington Agricultural Research Station freestall barn located in Arlington, WI. It is a 4-row, 104 stall, tail-to-tail barn that uses natural ventilation and is not insulated. The barn is oriented east to west and has dimensions of $100 \mathrm{ft}(30.5 \mathrm{~m})$ wide by $120 \mathrm{ft}$ $(36.6 \mathrm{~m})$ long and a roof pitch of 4/12. Eave sidewall height is $12 \mathrm{ft}(3.7 \mathrm{~m})$. The barn has a wood-post-frame structure, and $6 \times 6$ in $(15.2 \mathrm{~cm} \times 15.2 \mathrm{~cm})$ wood posts are located at the feed bunk line and at the front of the internal row of stalls. Ventilation is controlled by a 6.5in $(16.5 \mathrm{~cm})$ eve opening and 9-ft $(2.7 \mathrm{~m})$ adjustable curtains. The ridge opening is 24 in $(61 \mathrm{~cm})$. No fans or sprinklers are used. Stalls are 46 in $(1.2 \mathrm{~m})$ wide and $8 \mathrm{ft}(2.4 \mathrm{~m})$ long. Brisket boards are $1.5 \mathrm{in} \times 7.5$ in $(3.8 \mathrm{~cm} \times 19.1 \mathrm{~cm})$ boards attached to and below the stall dividers, approximately 66 in $(1.7 \mathrm{~m})$ from the rear curb and extend down to the top of the stall surface. Neck rails are mounted 45 in $(1.14 \mathrm{~m})$ above the top of the rear curb, or approximately $1.07 \mathrm{~m}$ above the stall surface. All stall bases, except sand, have a concrete base, with a 3 in $(7.6 \mathrm{~cm})$ upward slope toward the brisket board.

Figure 1 shows the freestall barn layout and observation recording sheet (not to scale). The stalls were identified by stall base type and stall number. Video cameras panned the stalls in a specific order and the stall numbers were assigned accordingly for identification purposes. The RLOC was defined as the following: stalls located near the feed alley were considered on the interior row, while stalls located on the outside of the building were on the exterior row. The two sides of the barn were: 1) the north side, which had a low stocking density (LowSD) and houses cows milked by a robot milker; and 2) the south side, had a higher stocking density (100\%SD) and houses cows milked $2 \mathrm{X}$ in a conventional parlor. Cows on the LowSD side can only enter the feed alley area by passing through the robot and leave the feed alley through a one-way gate located on the west end of the barn. Both sides had access to, and spent time at, the feed bunk after being milked. Because $100 \%$ SD cows were batch milked, and LowSD cows were sequentially milked, the percentage of cows at the feed bunk at one time was higher for $100 \%$ SD. The STLLOC was defined as the following: stalls on row ends or next 


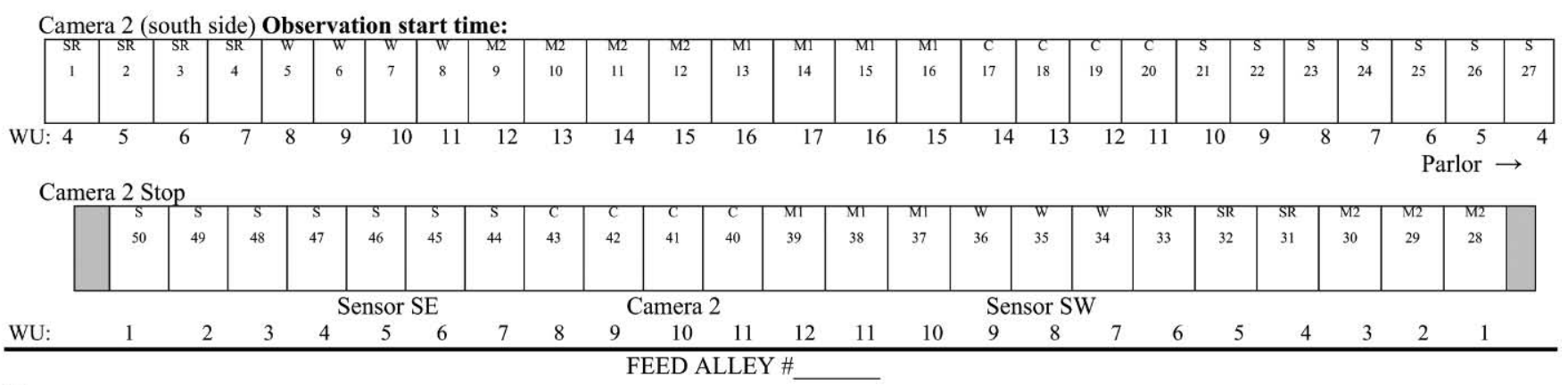

Tape:

Time:

\begin{tabular}{|c|c|c|}
\hline & & $\mathrm{S}=$ sand \\
\hline KEY & & $\mathrm{C}=$ concrete \\
\hline $\mathrm{E}=$ empty & $\mathrm{U}=$ unsure or cannot tell & $\mathrm{SR}=$ Comfort Mat \\
\hline $\mathrm{L}=$ lying down & $*=$ Cow lying outside of a stall & $\mathrm{W}=$ Waterbed \\
\hline $\mathrm{S}=$ standing in stall & $\mathrm{H}_{2} \mathrm{O}$ & M2 = Comfy cow \\
\hline $\mathrm{H}=$ half in and half out of stall standing & Stall number is camera sequence number. & M1 = Pasture mat \\
\hline
\end{tabular}

FEED ALLEY \#

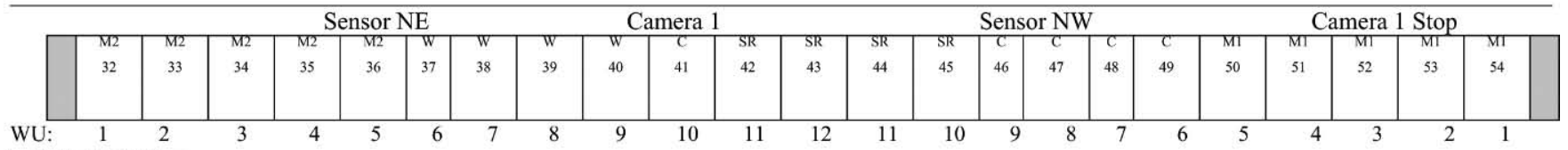
$\leftarrow$ Robotic Milker

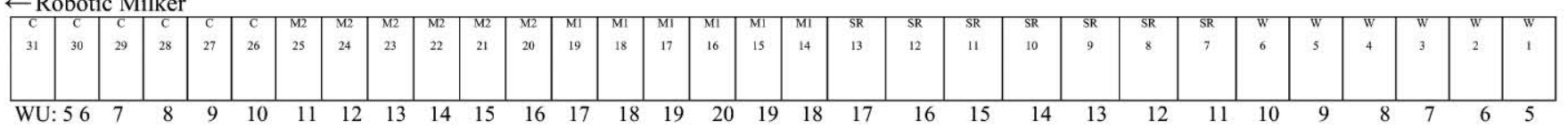

Camera 1 (north side) Observation start time:

Figure 1. Freestall barn layout and observation recording form. (Not to scale.)

to a different stall base were classified as END, and the remainder was classified as NOTEND.

The number located directly below each stall is the WDIST, which was measured in water units (WU); 1 WU was approximately 1 stall width. The WDIST was measured to the nearest water location. For example, stall number M1-14 on 100\%SD is 18 WU from either water location on that side of the barn side. The XPOSR indicated the amount of time cows were exposed to their pen and was summarized by the month of the observation. The Arlington freestall barn was a new facility, and cows were exposed to mattress-based tie-stalls before entering the study.

The stall bases included rubber mat (Comfort ZoneMilk Mat, Alfa Laval Agri, Kansas City, MO), waterbed (Atlanta Cow Waterbeds, Scottdale, GA), mattress type $1($ MATR1 $=$ Pasture Mat Mattresses, Seaforth, Ontario, Canada), mattress type $2($ MATR2 $=$ Comfy Cow Free Stall Mattresses, Byron Center, MI), concrete, and sand. Rubber mats were solid, ethylene vinyl acetate, material. The waterbed based stalls were made with two layers of a vulcanized rubber (100\% natural). Each layer had a fiber layer and six plies of rubber, and each stall was individually filled with three gal (11.4 l) of calcium chloride and 13 gal (49.2 l) of water. The MATR1-based stalls had three layers: the top layer was needle-punched polypropylene impregnated with wax to increase water shedding; the second layer was either a 1 in $(2.5 \mathrm{~cm})$ foam pad or a 0.75 in $(1.9 \mathrm{~cm})$ felt pad; and the bottom layer was a multi-celled, rubber crumb (crushed tire) filled mattress. The MATR2-based stalls contained a polyethylene interior of recycled foam and vinyl from the automobile industry with a Tafcoat waterproof cover.

Washed mason sand was used in sand stalls. Stalls were cleaned and leveled at milking time, and sand was added once a week to establish a level surface, from the top of the stall curb to the bottom of brisket board, for an approximate depth of 8 to 9 in (20.3 to 22.9 $\mathrm{cm})$. Sand usage was not recorded. Each stall base was grouped 3 to 7 stalls per section, and sections randomly placed in each row on each side. The sand stalls were 
not used on the LowSD because of concerns of sand settling in the top portion of the gravity-flow manurehandling system. The MATR1, MATR2, waterbed, and concrete-based stalls were bedded with sawdust twice per week and soiled bedding was removed following the scheduled milking (parlor system) or human-intervention time (automatic milking system). Stall bedding dates were not recorded, so stall usage by days since bedding was not analyzed. Rubber mat bases were refastened to the concrete base in July and bedding of these stalls was discontinued at the manufacturer's request.

An ADT Security Systems, Inc. (Menlo Park, CA) closed-circuit monitor camera system, with one camera on each side, was used to observe activity $24 \mathrm{~h}$ per $\mathrm{d}$. Digital images were recorded using a Pelco VCR and Simplex Monochrome Multiplexor.

Four observation times per day, 2:00 p.m., 8:00 p.m., 4:00 a.m., and 9:00 a.m., were observed from May 9, 2001 to February 9, 2002. The 9-mo data collection period was selected to represent normal seasonal temperature and relative humidity (RH\%) variation in the Midwest region of the United States. The 2:00 p.m. observation time was chosen to allow for potential delays in the regularly scheduled 12:00 p.m. tape change. Lights were off from 9:30 p.m. to 3:30 a.m. The 4:00 a.m. observation time was chosen to observe stall use after the lights were turned on in the freestall barn. The 8:00 p.m. and 9:00 a.m. observation times were chosen to be 2 hours after the scheduled parlor milking time, to allow for variation in milking time, and allow cows time to eat after they returned from the parlor.

The five, six, and eight-hour intervals were selected to make the assumption that the observations were independent from each other. This was determined from a preliminary analysis of data collected every 15 min that showed no stall was being occupied consistently for a 5 to 6 -h period. Therefore, all unoccupied stalls were assumed equally appealing (Hemken, 2002, personal communication). Similarities between means and standard deviations of each observation time, for each status, supported the conclusion that the four observation times were similar and accurately characterized stall occupancy across a day.

The following steps were used to view videotape images and record observations: First, stalls were observed in sequential order on $100 \%$ SD and assigned one of the following statuses: lying in stall, standing half-in-and-out of stall, standing in stall, empty stall, or unsure status. Unsure was assigned to stalls that could not be accurately categorized as any of the first four. Stalls were then observed similarly on the LowSD side.
Five HOBO H8 Pro Series (Onset Computer Corporation, Pocasset, MA) sensors recorded temperature every 15 minutes. One sensor was located in each quadrant of the barn, northwest (NW), northeast (NE), southwest (SW), southeast (SE) 38 to $40 \mathrm{ft}$ (11.6 to $12.2 \mathrm{~m}$ ) from each end wall, and 9 to $10 \mathrm{ft}(2.7$ to $3.0 \mathrm{~m})$ above the alley floor surface over the front of the interior row of stalls. One sensor was located in a radiation shield outside (OS) the barn on the north side, and $21 \mathrm{ft}$ (6.4 $\mathrm{m})$ from the barn and $3.5 \mathrm{ft}(1.1 \mathrm{~m})$ above the ground surface. Figure 1 shows the approximate location of the four inside sensors (NW, NE, SW, and SE).

Each stall was assigned temperature data from the closest sensor for each observation. Due to the different systems for collecting stall occupancy and barn temperature data, the actual stall's status observation time varied from the temperature by 0 to $10 \mathrm{~min}$. Stalls 1 to 13 and 40 to 50 on $100 \%$ SD were assigned the temperature recorded from sensor SE. Stalls 14 to 39 on $100 \% \mathrm{SD}$ were assigned the temperature recorded from the sensor SW. Stalls 1 to 16 and 43 to 54 on LowSD were assigned the temperature recorded from the sensor NW. Finally, stalls 17 to 42 on LowSD were assigned the temperature recorded from the sensor NE.

A total of 961 stall use observations from $100 \% \mathrm{SD}$ and 983 stall use observations for LowSD were used in the analysis for the 9-mo period. A total of 119 complete observations (both sides) and 34 half observations (one side) were missing. The reasons for missing observations were: image not recorded, tape not switched on time, camera(s) not panning/moving across stalls, camera(s) not running/recording, and not enough light to see stall occupancy.

Percentages of each status were calculated as the number of stall-day-status observations divided by total number of stall-day observations for the different categories or factors tested across the 9-mo period. Stall occupied percentages were calculated using the number of stall-day-lying, standing, and standing half-in-andout observations divided by total number of stall-day observations.

Percentages for the different factors were analyzed using logistic regression with the GENMOD Procedure in Statistical Analysis Software (SAS, SAS Institute, Cary, NC, 1999) and contrast statements were used to determine significant differences between percentages (Stokes et al., 1995). Each side was analyzed separately to eliminate errors due to different stocking densities of the $100 \%$ SD and LowSD sides. Stocking densities were a function of herd management and not intentionally set as part of the study's design.

The CATMOD Procedure in SAS was used to model lying and occupied as binary outcomes. Independent variables considered continuous were XPOSR, WDIST, 
Table 1. Lying and occupied model analyzes' variables, chi-square values, and p-values.

\begin{tabular}{|c|c|c|c|c|}
\hline \multirow[b]{2}{*}{ Variable } & \multicolumn{2}{|c|}{ Lying Model } & \multicolumn{2}{|c|}{ Occupied Model } \\
\hline & Chi-Square & $\mathrm{P}$-value & Chi-Square & $\mathrm{P}$-value \\
\hline Intercept & 28.08 & $<0.0001$ & 54.28 & $<0.0001$ \\
\hline stall base $^{1}$ & 171.88 & $<0.0001$ & 359.64 & $<0.0001$ \\
\hline $\mathrm{RLOC}^{1,2}$ & 0.75 & 0.3872 & 40.14 & $<0.0001$ \\
\hline STLLOC ${ }^{1,3}$ & 444.96 & $<0.0001$ & 505.76 & $<0.0001$ \\
\hline $\operatorname{side}^{1}$ & 0.01 & 0.9026 & 2.56 & 0.1097 \\
\hline $\mathrm{XPOSR}^{4}$ & 3.16 & 0.0754 & 9.34 & 0.0022 \\
\hline WDIST $^{4}$ & 480.35 & $<0.0001$ & 591.12 & $<0.0001$ \\
\hline temperature ${ }^{4}$ & 478.61 & $<0.0001$ & 507.05 & $<0.0001$ \\
\hline stall base $\times$ RLOC & 73.30 & $<0.0001$ & 148.59 & $<0.0001$ \\
\hline stall base $\times$ STLLOC & 234.33 & $<0.0001$ & 350.64 & $<0.0001$ \\
\hline stall base $\times$ side & 175.96 & $<0.0001$ & 415.97 & $<0.0001$ \\
\hline stall base $\times$ XPOSR & 248.65 & $<0.0001$ & 315.07 & $<0.0001$ \\
\hline stall base $\times$ WDIST & 48.28 & $<0.0001$ & 20.91 & 0.0008 \\
\hline stall base $\times$ temperature & 75.56 & $<0.0001$ & 157.65 & $<0.0001$ \\
\hline RLOC $\times$ side & 30.77 & $<0.0001$ & 37.31 & $<0.0001$ \\
\hline RLOC $\times$ temperature & 39.76 & $<0.0001$ & 142.99 & $<0.0001$ \\
\hline STLLOC $\times$ side & N/A & N/A & 9.26 & 0.0023 \\
\hline side $\times$ WDIST & 54.17 & $<0.0001$ & 155.60 & $<0.0001$ \\
\hline
\end{tabular}

${ }^{1}$ Independent variables considered categorical in model analyzes.

${ }^{2} \mathrm{RLOC}$ represents interior and exterior row categories.

${ }^{3}$ STLLOC represents END and NOTEND categories.

${ }^{4}$ Independent variables considered continuous in model analyzes.

and temperature. Independent variables considered categorical were stall base, RLOC, STLLOC, and side. Any 2-way interactions considered biologically significant or meaningful were also analyzed.

\section{RESULTS AND DISCUSSION}

The results of the model analyses show stall base, WDIST, STLLOC, RLOC, temperature, and XPOSR all affect stall use. Table 1 shows the lying and occupied model analyzes variables, chi-square values, and $P$-values. Stall design was not considered a factor since each stall was of the same design.

The side effect explained the least amount of variation in both models. This indicates side had the least impact on whether cows used the stalls. The side variable was included in the model to determine the effects of stocking rates and barn orientation differences. Stocking density was not included as a variable because of its close relationship with side. Model results showed WDIST and temperature best explained the variation in lying status, and stall base and STLLOC, were other significant $(P<0.0001)$ predictors of lying status. The effects of WDIST and temperature on lying status suggest the importance of crossovers, containing access to water, to improve stall use.

The stall base effect had significant $(P<0.0001)$ interactions with RLOC, STLLOC, side, XPOSR, WDIST, and temperature. This indicates a cow's preference to lie down on a particular stall base varied for each of these factors. The RLOC effect had significant $(P<$
0.0001) interactions with temperature and side indicating lying percentages on interior and exterior rows were different for the temperature intervals and two sides. This may reflect cows' tendency to avoid outside rows of stalls during periods of high temperatures. The WDIST effect had a significant $(P<0.0001)$ interaction with side. The cow's preference to lie in a stall a certain WDIST away varied by side. RLOC, side, and XPOSR were not significant predictors $(P<0.05)$, but were kept in the model due to interaction with other factors.

The WDIST effect best explained the variation in stall occupied $(P<0.0001)$, but stall base, RLOC, STLLOC, XPOSR, and temperature effects were also significant $(P<0.01)$ predictors. The stall base effect had a significant $(P<0.001)$ interaction with RLOC, STLLOC, side, XPOSR, WDIST, and temperature. The RLOC effect had a significant $(P<0.0001)$ interaction with temperature and side. The WDIST and STLLOC effects had significant $(P<0.01)$ interactions with side.

Table 2 shows the stall occupancy percentages by stall base for each side. The current study showed cows on the $100 \%$ SD side spent the highest $(P<0.05)$ percentage of time lying in sand (68.7\%). Mattresses (MATR1 [65.2\%] and MATR2 [57.4\%]) followed closely as the next most preferred $(P<0.05)$, followed by waterbed (45.4\%), rubber mat (32.9\%), and the least preferred ( $P$ $<0.05)$ was concrete $(22.8 \%)$. Mattresses (MATR1 and MATR2) had the highest $(P<0.05)$ stall occupied percentages $(88.3 \%$ and $84.1 \%)$ followed by sand $(79.0 \%)$, rubber mat $(64.8 \%)$, waterbed $(61.6 \%)$, and concrete (38.7\%). The mattresses' higher stall occupied percent- 
Table 2. Stall occupancy percentages ${ }^{1}$ by stall base ${ }^{2}$ for each side. ${ }^{3}$

\begin{tabular}{|c|c|c|c|c|c|c|c|c|}
\hline & rubber mat & waterbed & MATR2 & MATR1 & concrete & sand & $\bar{x}^{4}$ & S.E. ${ }^{5}$ \\
\hline \multicolumn{9}{|l|}{$100 \%$ SD $(\text { south })^{6}$} \\
\hline Empty & $34.7^{\mathrm{c}}$ & $38.2^{\mathrm{b}}$ & $15.5^{\mathrm{e}}$ & $11.7^{\mathrm{f}}$ & $61.2^{\mathrm{a}}$ & $19.8^{\mathrm{d}}$ & 29.3 & 0.5 \\
\hline Half-in-and-out & $7.3^{\mathrm{b}}$ & $8.3^{\mathrm{a}}$ & $6.0^{\mathrm{c}}$ & $6.1^{\mathrm{c}}$ & $7.0^{\mathrm{b}}$ & $7.0^{\mathrm{b}}$ & 7.0 & 0.3 \\
\hline Lying & $32.9^{\mathrm{e}}$ & $45.4^{\mathrm{d}}$ & $57.4^{\mathrm{c}}$ & $65.2^{\mathrm{b}}$ & $22.8^{\mathrm{f}}$ & $68.7^{\mathrm{a}}$ & 51.0 & 0.6 \\
\hline Standing & $24.6^{\mathrm{a}}$ & $7.9^{\mathrm{e}}$ & $20.7^{\mathrm{b}}$ & $17.0^{\mathrm{c}}$ & $8.8^{\mathrm{d}}$ & $3.3^{\mathrm{f}}$ & 12.1 & 0.4 \\
\hline Occupied $^{7}$ & $64.8^{\mathrm{d}}$ & $61.6^{\mathrm{e}}$ & $84.1^{\mathrm{b}}$ & $88.3^{\mathrm{a}}$ & $38.7^{\mathrm{f}}$ & $79.0^{\mathrm{c}}$ & 70.1 & 0.5 \\
\hline Unsure & $0.5^{\mathrm{b}}$ & $0.2^{\mathrm{c}}$ & $0.4^{\mathrm{b}}$ & $0.1^{\mathrm{c}}$ & $0.2^{\mathrm{c}}$ & $1.2^{\mathrm{a}}$ & 0.5 & 0.3 \\
\hline Total number 8 & 6727 & 6727 & 6727 & 6727 & 7688 & 13,454 & N/A & N/A \\
\hline $\mathrm{CCI}^{9}$ & 49 & 26 & 32 & 26 & 41 & 13 & N/A & N/A \\
\hline \multicolumn{9}{|l|}{ LowSD (north) $)^{10}$} \\
\hline Empty & $81.0^{\mathrm{b}}$ & $65.4^{\mathrm{c}}$ & $44.7^{\mathrm{d}}$ & $40.4^{\mathrm{e}}$ & $83.7^{\mathrm{a}}$ & N/A & 61.4 & 0.5 \\
\hline Half-in-and-ou & $2.2^{\mathrm{c}}$ & $4.1^{\mathrm{a}}$ & $4.2^{\mathrm{a}}$ & $3.4^{\mathrm{b}}$ & $2.9^{b}$ & N/A & 3.4 & 0.2 \\
\hline Lying & $11.8^{\mathrm{d}}$ & $25.6^{\mathrm{c}}$ & $39.1^{\mathrm{b}}$ & $45.3^{\mathrm{a}}$ & $10.3^{\mathrm{e}}$ & N/A & 27.6 & 0.4 \\
\hline Standing & $5.1^{\mathrm{c}}$ & $3.9^{\mathrm{d}}$ & $11.9^{\mathrm{a}}$ & $10.8^{\mathrm{b}}$ & $3.0^{\mathrm{e}}$ & N/A & 7.3 & 0.2 \\
\hline Occupied $^{7}$ & $19.0^{\mathrm{d}}$ & $33.6^{\mathrm{c}}$ & $55.2^{\mathrm{b}}$ & $59.6^{\mathrm{a}}$ & $16.2^{\mathrm{e}}$ & N/A & 38.3 & 0.5 \\
\hline Unsure & $0.0^{\mathrm{c}}$ & $1.1^{\mathrm{a}}$ & $0.1^{\mathrm{b}}$ & $0.1^{\mathrm{b}}$ & $0.1^{\mathrm{b}}$ & N/A & 0.3 & 0.1 \\
\hline Total number 8 & 10,813 & 9830 & 10,812 & 10,813 & 7130 & N/A & N/A & N/A \\
\hline $\mathrm{CCI}^{9}$ & 38 & 24 & 29 & 24 & 36 & N/A & N/A & N/A \\
\hline
\end{tabular}

a,b,c,d,e,fPercentages within rows with different superscripts differ $(P<0.05)$.

${ }^{1}$ Percentage $=$ Number of stall-day-status observations/ Total number of stall-day observations by stall base by side.

${ }^{2}$ Stall bases: rubber mat $=$ Comfort Zone-Milk Mat, waterbed $=$ Atlanta Cow Waterbeds, MATR2 $=$ Comfy Cow Free Stall Mattress, MATR1 = Pasture Mat Mattresses, concrete = concrete, and sand = sand stalls.

${ }^{3}$ Data collected from May 9, 2001 to February 9, 2002.

${ }^{4}$ Mean percentage equals Total stall-day-status observations / Total number stall-day observations by side.

${ }^{5}$ S.E. refers to the pooled standard error for each status by side.

${ }^{6} 100 \%$ SD (south) refers to the south side of the freestall barn with $100 \%$ stocking density.

${ }^{7}$ Occupied is defined as Lying + Standing + Half-in-and-out.

${ }^{8}$ Total Number is equal to Total number of stall-day observations by stall base by side.

${ }^{9} \mathrm{CCI}$ refers to cow comfort index percentage $=$ Number of stall-day-half in and out and standing observations / Number of stall-day-occupied observations (Cook, 2002).

${ }^{10}$ LowSD (north) refers to the north side of the freestall barn with low stocking density.

age over all other stall bases, including sand, was caused by the higher percentage of time cows spent standing on these stall bases. The $100 \%$ SD results show cows spend more time lying in sand stalls, but occupied mattress based stalls more, which implies these two measures can be expected to rank cow preference for the different bases differently. Both measures consistently ranked concrete to be inferior to all other surfaces; mattresses superior to waterbed and rubber mat; and MATR1 superior to MATR2 on both sides. Side had a small effect on cow preference rankings, for the different stall bases, as shown by only rubber mat and waterbed having rank variation. This finding may be helpful in comparing cow preference for different stall bases across different experiments.

Cows on LowSD spent the highest $(P<0.05)$ percentage of time lying (45.3\%) and occupying (59.6\%) MATR1 followed by MATR2 (39.1 and $55.2 \%$, respectively); sand was not an option. This suggests not all mattress types are equally desirable to cows, and should be considered when comparisons are made between a mattress base and other freestall bases. The side $\times$ stall base interac- tion was significant; therefore, cow preference for a particular stall base differed between the two sides. The waterbed stall occupied percentage (33.6\%) exceeded ( $P$ $<0.05)$ the rubber mat based stalls $(19.0 \%)$. This may have been attributed to location of waterbed in relation to the robot and one-way gate system. The waterbed based stalls were the first group of stalls on exterior as cows passed through the one-way gate returning from the feed alley. Cows may have preferred to occupy the closest available stalls upon returning from the feed alley. Since stocking density and competition for stalls was lower on LowSD, more cows could occupy their first choice. The higher occupied percentage for rubber mat on $100 \%$ SD may be overflow from more preferred stalls.

Lying and occupied percentages for sand stalls were higher than in previous studies. Visser (1994) showed a $10 \%$ occupancy rate with sand alone when compared to other stall bases of sand with a canvas cover (60\%) and maize choppings with a canvas cover $(21 \%)$. However, a 38.4\% occupancy rate for sand was found by Thoreson et al. (2000). The $40 \%$ to $69 \%$ higher lying and occupied percentages found in the current study 
may be attributed to maintenance of sand levels in stalls, sand quality, alternative stall options, and or time of day of the observation. Previous studies' measures of occupancy (lying, standing, and/or standing half in and out) were not defined. This may have contributed to differences found between current and previous results.

Mattresses' (MATR1 and MATR2) stall occupied percentages were similar to those found in previous studies. Rodenburg and House (2000) reviewed results of 86.2\% occupancy and Sonck and Daelemans (1999) found greater than $50 \%$ occupancy on rubber-filled mattresses.

Lying percentage trends across stall bases differed from previous studies. Rubber-filled mattresses resulted in $43.3 \%$ lying versus $26.4 \%$ in sand in a study reviewed by Rodenburg and House (2000). The depth of sand in the sand based stalls and sand quality may have attributed to the differences in lying percentages between current and previous studies. The waterbed stalls percentage (45.4\%) was similar to the $45.95 \%$ average lying percentage reported by Sonck and Daelemans (1999). The rubber mat stalls percentage (32.9\%) was slightly lower than the $51.08 \%$ reported by Sonck and Daelemans (1999).

Order of stall occupied percentages for mattresses (MATR1 and MATR2), rubber mat, sand, and waterbed was similar to previous studies. Chaplin et al. (2000), House et al. (1994), and Rodenburg and House (2000) found occupancy percentages to be higher on rubberfilled mattresses versus sand. Rodenburg and House (2000) and Sonck and Daelemans (1999) found lower occupancy rates on waterbeds compared to rubber-filled mattresses. Muller and Botha (1997) found cows would rise more and lie down less if the stall base was hard.

Cook (2002) proposed the use of a cow comfort index (CCI $=$ number of cows standing divided by the total number of cows standing and lying in a stall) to evaluate cow comfort for different stall bases. Bases with lower CCI values were considered more comfortable than stall bases with a higher CCI value. The CCI values were calculated using the current study results (Table 2), and ranged from 13\% (sand) to $49 \%$ (rubber mat) on $100 \%$ SD and from 24 (MATR1) to $38 \%$ (rubber mat) on LowSD. Current and previous research used stall usage as an indicator of cow preference. The CCI index appears to unfairly penalize bases with a high percentage of cows standing in the stalls. The CCI index values calculated with the current data consistently ranked stall bases differently for cow comfort from stall bases ranked on stall use in the current and previous studies. The sand CCI value (13\%) implied it was twice as good as MATR1 $(26 \%)$ on $100 \%$ SD. The waterbed based stalls (32\%) were ranked over MATR2 (26\%), and concrete

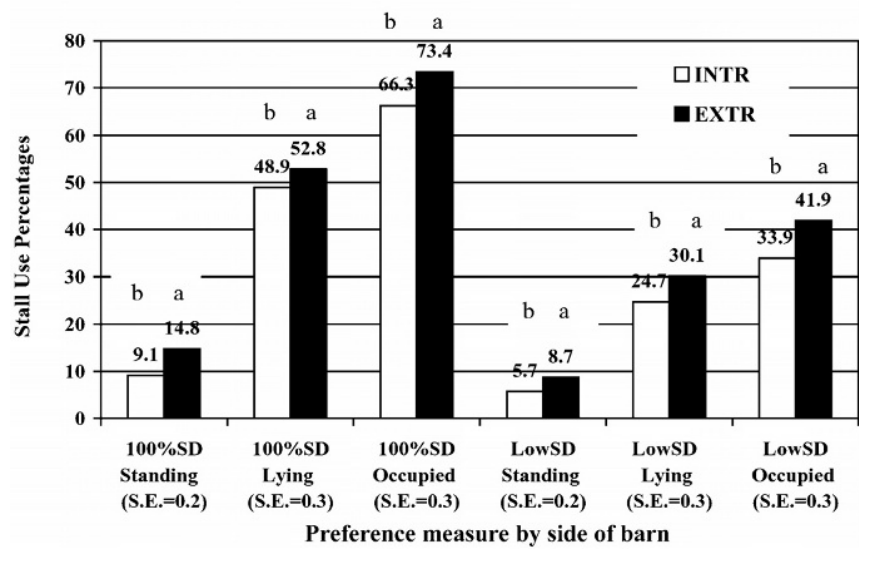

Figure 2. Percentage of stalls with cows standing, cows lying or stalls occupied for interior and exterior rows by side of barn. Occupied $=$ Lying + Standing + Half-in-and-out. Percentages $=($ Number of stall-day-preference measure observations / Total number of stallday observations). Interior $=$ interior and exterior $=$ exterior row of stalls. Side of barn $=[100 \% \mathrm{SD}=100 \%$ stocking density side and LowSD = low stocking density $(66 \%)$ side]. Percentages within preference measure, by side, with different letters $(a, b)$ differ $(P<0.05)$. S.E. $=$ preference measures' pooled standard error.

(41\%) over rubber mat (49\%) on $100 \%$ SD. Waterbed (24\%) was ranked equal to MATR2 (24\%) and concrete (36\%) over rubber mat (38\%) on the LowSD. Based on the current study's ranking of cow preference by stall usage, an alternative method of measuring cow preference and comfort is needed. This alternative method to evaluate stalls for cow comfort should incorporate percentage of cows lying in and occupying stalls and stocking density.

Figure 2 shows the percentage of stalls with cows standing, cows lying, or stalls occupied of interior and exterior rows by side. The current study results show cows preferred to lie down, stand in, and occupy stalls on the exterior row on both sides of the barn $(P<0.05)$. The exterior row on $100 \%$ SD had $52.8 \%$ lying, $14.8 \%$ standing, and $73.4 \%$ occupied. The exterior row on LowSD had $30.1 \%$ lying, $8.7 \%$ standing, and $41.9 \%$ occupied. Cows may have occupied stalls located near the curtain sidewall for improved ventilation or temperature regulation.

Figure 3 shows the percentage of stalls with cows standing, cows lying or stalls occupied of END and NOTEND of a stall base section by side. NOTEND stalls were preferred to END stalls for lying and occupied on both sides of the barn $(P<0.05)$. The END stalls were preferred for standing on 100\%SD. This may have been attributed to the location of END stalls next to other stall bases. A change in the stall base level, or gap between base types, may make them less comfortable to lie in or more difficult for cows to rise. 


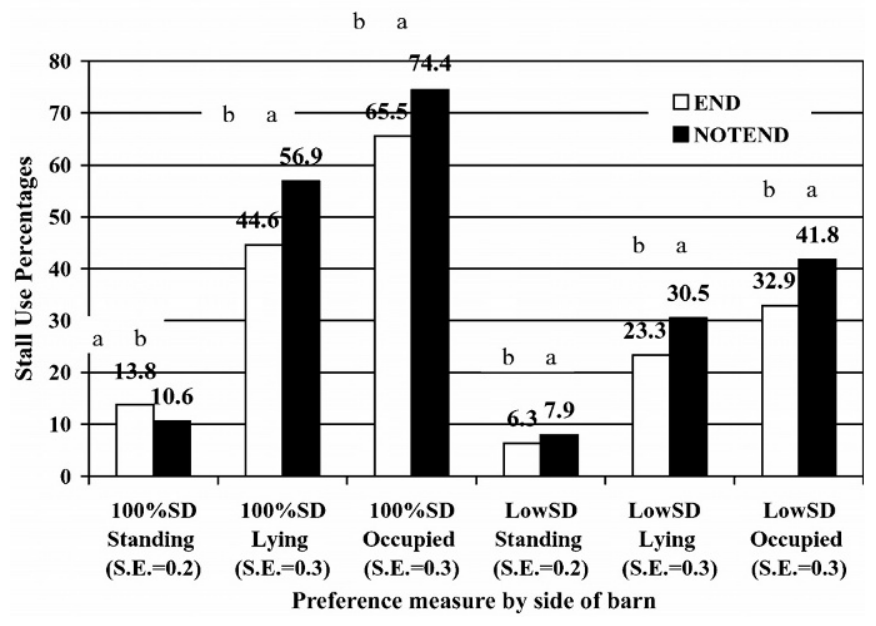

Figure 3. Percentage of stalls with cows standing, cows lying or stalls occupied for END and NOTEND stall locations by side of barn. Occupied $=$ Lying + Standing + Half-in-and-out. Percentages $=(N u m-$ ber of stall-day-preference measure observations / Total number of stall-day observations). END = end stall of a stall section and NOTEND $=$ not end of a stall section. Side of barn $=[100 \% \mathrm{SD}=100 \%$ stocking density side and LowSD = low stocking density (66\%) side]. Percentages within preference measure, by side, with different letters $(\mathrm{a}, \mathrm{b})$ differ $(P<0.05)$. S.E. $=$ preference measures' pooled standard error.

Due to the significant effect of STLLOC, an analysis of percentage of statuses by stall base for each side, with NOTEND stalls only, was conducted to determine if stall base preference ranking would differ for the combination of NOTEND and END stalls. The resulting stall use values showed the same cow preference rank order for the different stall bases. A few exceptions were the difference in significance level of stall occupied percentages on $100 \%$ SD; MATR1 and MATR2 were not different $(P<0.05)$ and waterbed had a higher $(68.8 \%)$ stall occupied percentage than rubber mat (64.8\%). The LowSD side had no significant $(P<0.05)$ difference between concrete and rubber mat for lying or stall occupied percentages ((11.1 and $10.9 \%)$ and (17.6 and $17.8 \%)$, respectively). The difference in stall base rankings, for lying or stall occupied, by excluding END stalls was not found to be important enough to exclude them from further analyses.

Location results were in agreement with Natzke et al. (1982), which found stall use was less in stalls on the interior row and located on the ends of the row. The stall base $\times$ RLOC and stall base $\times$ STLLOC interactions were significant, indicating cow preference for a stall base varied by location. The RLOC $\times$ temperature interaction was also significant, therefore stall use for stalls on the interior and exterior rows varied by temperature.

Table 3 shows the percentage of stalls with cows lying for each stall base by month for each side. The length of XPOSR influenced lying percentages. Lying percentages varied month to month for stall bases. The stall base $\times$ XPOSR interaction was significant $(P<0.05)$, which indicates stall use for particular stall bases was different for different levels of XPOSR. Sand had the largest variation by month (43\% June to $75.8 \%$ December). Temperature and level of sand in the stalls may have attributed to this variation. On $100 \%$ SD, gradual declines in cow preference were observed for rubber mat. The rubber mat based stalls started at $49.3 \%$ lying in May and ended at 28.6\% in February. Use of waterbed based stalls increased with time, the percentage lying increased from $43.7 \%$ in May to $54.0 \%$ in February. Percentage lying for waterbed was similar to MATR1 and MATR2 by February. Mattresses' (MATR1 and MATR2) lying percentages had the smallest fluctuation over the 9-mo period.

The sand based stalls had the highest lying percentages of all stall bases in the fall and winter (September to February) and their usage increased over earlier months. This is different from results reported earlier (Thoreson et al., 2000). This difference can be partially explained by temperature, in that this research was conducted during a mild winter. Similar results were obtained when stall usage was analyzed by temperature, showing sand stall usage decreased and was lower than some other stall bases during cold weather (see Figures 4 and 6). The stall base with the highest percentage of cows lying varied by month. Sand, MATR1 and MATR2 had the highest values the first month, MATR1 the highest during the second month, sand and MATR1 the highest months 3 and 4, with sand being the highest the last six months of the trial. Mean percentage lying across all stall bases was low in June (42.2\%), which may have been attributed to low cow numbers (46) in comparison to the other months and or slightly higher temperatures in comparison to May. Mean percentage lying was high in December at $55.1 \%$. Stocking densities ranged from $92 \%$ in June to $106 \%$ in August, October, December, January, and February.

LowSD had similar trends. However, mattresses (MATR1 and MATR2) had the highest $(P<0.05)$ percentage lying with MATR1 significantly $(P<0.05)$ higher in May, August, and October through January. The concrete based stalls had a higher $(P<0.05)$ lying percentage than rubber mat in November (14.2 to 8.6\%) and December (17.2 to 12.3\%). Mean percentage lying across all stall bases was lower in November (30.6\%) and December (29.9\%) compared to months with similar cow numbers. Stocking densities increased from $54 \%$ in May to $72 \%$ in February.

Table 4 shows the percentage of stalls occupied for each stall base by month for each side. The length of XPOSR influenced stall occupied percentages. Trends 
Table 3. Percentage ${ }^{1}$ of stalls with cows lying for each stall base $e^{2}$ and mean number of cows $\left( \pm\right.$ SE) by month for each side. ${ }^{3}$

\begin{tabular}{|c|c|c|c|c|c|c|c|c|c|}
\hline & Number of cows ${ }^{4}$ & rubber mat & waterbed & MATR2 & MATR1 & concrete & sand & $\bar{x}^{5}$ & S.E. ${ }^{6}$ \\
\hline \multicolumn{10}{|c|}{$100 \%$ SD (south) ${ }^{7}$} \\
\hline May & $47 \pm 0.9$ & $49.3^{b}$ & $43.7^{b}$ & $55.7^{\mathrm{a}}$ & $58.4^{\mathrm{a}}$ & $12.9^{\mathrm{c}}$ & $59.6^{\mathrm{a}}$ & 47.7 & 2.0 \\
\hline June & $46 \pm 0.3$ & $39.6^{\mathrm{c}}$ & $42.9^{\mathrm{c}}$ & $55.1^{\mathrm{b}}$ & $61.4^{\mathrm{a}}$ & $14.6^{\mathrm{d}}$ & $43.0^{\mathrm{c}}$ & 42.2 & 1.8 \\
\hline August & $53 \pm 0.2$ & $26.2^{\mathrm{d}}$ & $43.8^{\mathrm{c}}$ & $58.7^{\mathrm{b}}$ & $66.1^{\mathrm{a}}$ & $25.6^{\mathrm{d}}$ & $66.9^{\mathrm{a}}$ & 50.1 & 2.1 \\
\hline September ${ }^{9}$ & $52 \pm 0.2$ & $35.3^{\mathrm{e}}$ & $43.6^{\mathrm{d}}$ & $57.0^{\mathrm{c}}$ & $64.9^{\mathrm{b}}$ & $19.9^{\mathrm{f}}$ & $69.0^{\mathrm{a}}$ & 50.6 & 1.5 \\
\hline October & $53 \pm 0.2$ & $37.3^{\mathrm{d}}$ & $44.2^{\mathrm{c}}$ & $59.6^{\mathrm{b}}$ & $63.1^{\mathrm{b}}$ & $23.5^{\mathrm{e}}$ & $77.1^{\mathrm{a}}$ & 53.9 & 1.5 \\
\hline November & $49 \pm 0.6$ & $34.0^{\mathrm{d}}$ & $41.1^{\mathrm{c}}$ & $62.4^{\mathrm{b}}$ & $63.2^{\mathrm{b}}$ & $30.5^{\mathrm{d}}$ & $73.7^{\mathrm{a}}$ & 53.6 & 1.5 \\
\hline February & $53 \pm 0.3$ & $28.6^{\mathrm{c}}$ & $54.0^{\mathrm{b}}$ & $54.5^{\mathrm{b}}$ & $63.0^{\mathrm{b}}$ & $25.0^{\mathrm{c}}$ & $74.1^{\mathrm{a}}$ & 52.7 & 2.9 \\
\hline \multicolumn{10}{|c|}{ LowSD (north) ${ }^{10}$} \\
\hline May & $29 \pm 0.8$ & $16.5^{\mathrm{c}}$ & $7.3^{\mathrm{d}}$ & $22.6^{\mathrm{b}}$ & $31.6^{\mathrm{a}}$ & $5.0^{\mathrm{d}}$ & N/A & 17.5 & 1.3 \\
\hline June & $35 \pm 0.3$ & $12.6^{\mathrm{b}}$ & $12.5^{\mathrm{b}}$ & $39.2^{\mathrm{a}}$ & $41.4^{\mathrm{a}}$ & $5.6^{\mathrm{c}}$ & N/A & 23.7 & 1.3 \\
\hline July $^{8}$ & $31 \pm 0.7$ & $9.8^{\mathrm{c}}$ & $21.2^{\mathrm{b}}$ & $42.6^{\mathrm{a}}$ & $42.9^{\mathrm{a}}$ & $4.8^{\mathrm{d}}$ & N/A & 25.8 & 1.2 \\
\hline August & $34 \pm 0.5$ & $9.0^{\mathrm{d}}$ & $23.0^{\mathrm{c}}$ & $35.0^{\mathrm{b}}$ & $38.8^{\mathrm{a}}$ & $8.5^{\mathrm{d}}$ & N/A & 23.9 & 1.2 \\
\hline February & $39 \pm 0.0$ & $11.8^{\mathrm{b}}$ & $53.3^{\mathrm{a}}$ & $50.2^{\mathrm{a}}$ & $53.9^{\mathrm{a}}$ & $14.3^{\mathrm{b}}$ & N/A & 38.1 & 2.7 \\
\hline
\end{tabular}

a,b,c,d,e,fPercentages within rows with different superscripts differ $(P<0.05)$.

${ }^{1}$ Percentage $=$ Number of stall-day-lying observations $/$ Total number stall-day observations by stall base for each month by side.

${ }^{2}$ Stall bases: rubber mat $=$ Comfort Zone-Milk Mat, waterbed $=$ Atlanta Cow Waterbeds, MATR2 = Comfy Cow Free Stall Mattress, MATR1 $=$ Pasture Mat Mattresses, concrete $=$ concrete, and sand $=$ sand stalls.

${ }^{3}$ Data collected from May 9, 2001 to February 9, 2002.

${ }^{4}$ Mean $( \pm \mathrm{SE})$ number of cows during each month by side.

${ }^{5}$ Mean percentage lying equals Total stall-day-lying observations / Total number stall-day observations for each month by side.

${ }^{6}$ S.E. refers to the pooled standard error for each month by side.

${ }^{7} 100 \%$ SD (south) refers to the south side of the freestall barn with $100 \%$ stocking density.

${ }^{8}$ Rubber mat were refastened to the respective stalls.

${ }^{9}$ Waterbed were adjusted by adding additional water and replacing clamps.

${ }^{10}$ LowSD (north) refers to the north side of the freestall barn with low stocking density.

were similar to lying percentages. The concrete based stalls consistently had the lowest occupied percentages from month to month. The MATR1 based stalls were consistently the highest from month to month and MATR2 and sand ranked high throughout the 9-mo period with MATR1 finishing at 91.0\%, MATR2 at $78.3 \%$, and sand at $82.0 \%$. There was a gradual increase in occupied percentages for waterbed and concrete. The waterbed based stalls started at $56.1 \%$, ended at $66.7 \%$ and concrete started at $24.6 \%$ and ended at $43.5 \%$. The rubber mat based stalls experienced a gradual decrease starting at $76.2 \%$ occupied and falling to $59.8 \%$ in February. Trends in stall occupied rates for the LowSD, from month to month, were similar to LowSD lying trends.

The waterbed based stalls' trend is in agreement with previous studies showing that the unstable surface of waterbeds may require a longer adaptation time (Sonck and Daelemans, 1999; Rodenburg and House, 2000). Cows exposed to mats had a longer adjustment period than those exposed to mattresses (Chaplin et al., 2000).
However, the current results show a decline in preference for rubber mat with increased XPOSR, which may be attributed to the refastening of rubber mat bases in July and the discontinuation of bedding these stalls according to manufacturer recommendation.

Figure 4 shows the percentage of stalls with cows lying on the $100 \%$ SD side for stall base by temperature $\left({ }^{\circ} \mathrm{F}\right)$ interval. The temperature effect influenced lying and stall occupied percentages for each stall base; stall use decreased as temperature increased. This was supported by the significant $(P<0.05)$ stall base $\times$ temperature, which indicates a cow preference for different stall base types at different temperature intervals. Cows preferred $(P<0.05)$ to lie down on sand $(79.2$ to $72.3 \%)$ when temperature was 21 to $60^{\circ} \mathrm{F}\left(-6.1\right.$ to $\left.15.6^{\circ} \mathrm{C}\right)$ and MATR1 (80.9 to $64.3 \%$ ) when temperature was 1 to $20^{\circ} \mathrm{F}\left(-17.2\right.$ to $\left.-6.7^{\circ} \mathrm{C}\right)$ and 61 to $100^{\circ} \mathrm{F}\left(16.1\right.$ to $\left.37.8^{\circ} \mathrm{C}\right)$. Waterbed $(56.5 \%)$ had a higher $(P<0.05)$ lying percentage during cold temperature 1 to $20^{\circ} \mathrm{F}\left(-17.2\right.$ to $\left.-6.7^{\circ} \mathrm{C}\right)$ than rubber mat $(29.8 \%)$ and concrete $(20.7 \%)$, and lower $(31.0 \%)$ lying percentage during warm tempera- 
Table 4. Percentage ${ }^{1}$ of stalls occupied ${ }^{2}$ for each stall base ${ }^{3}$ and mean number of cows $\left( \pm\right.$ SE) by month for each side. ${ }^{4}$

\begin{tabular}{|c|c|c|c|c|c|c|c|c|c|}
\hline & Number of cows ${ }^{5}$ & rubber mat & waterbed & MATR2 & MATR1 & concrete & sand & $\bar{x}^{6}$ & S.E. ${ }^{7}$ \\
\hline \multicolumn{10}{|c|}{$100 \%$ SD (south $)^{8}$} \\
\hline May & $47 \pm 0.9$ & $76.2^{\mathrm{b}}$ & $56.1^{\mathrm{c}}$ & $83.6^{\mathrm{a}}$ & $86.1^{\mathrm{a}}$ & $24.6^{\mathrm{d}}$ & $75.5^{\mathrm{b}}$ & 67.4 & 1.8 \\
\hline June & $46 \pm 0.3$ & $73.6^{\mathrm{c}}$ & $61.4^{\mathrm{d}}$ & $83.3^{\mathrm{b}}$ & $87.9^{\mathrm{a}}$ & $29.0^{\mathrm{f}}$ & $52.9^{\mathrm{e}}$ & 62.3 & 1.7 \\
\hline July $^{9}$ & $51 \pm 0.6$ & $48.8^{\mathrm{d}}$ & $53.2^{\mathrm{d}}$ & $80.2^{\mathrm{b}}$ & $86.9^{a}$ & $35.6^{\mathrm{e}}$ & $75.1^{\mathrm{c}}$ & 64.4 & 1.6 \\
\hline August & $53 \pm 0.2$ & $57.9^{\mathrm{e}}$ & $63.9^{\mathrm{d}}$ & $84.4^{\mathrm{b}}$ & $88.5^{\mathrm{a}}$ & $44.9^{\mathrm{f}}$ & $76.9^{\mathrm{c}}$ & 70.0 & 1.4 \\
\hline September ${ }^{10}$ & $52 \pm 0.2$ & $76.2^{\mathrm{c}}$ & $66.4^{\mathrm{d}}$ & $87.6^{\mathrm{a}}$ & $90.6^{\mathrm{a}}$ & $35.6^{\mathrm{e}}$ & $79.8^{b}$ & 72.9 & 1.3 \\
\hline October & $53 \pm 0.2$ & $70.0^{\mathrm{c}}$ & $60.3^{\mathrm{d}}$ & $90.7^{\mathrm{a}}$ & $90.4^{\mathrm{ab}}$ & $42.3^{\mathrm{e}}$ & $88.0^{\mathrm{b}}$ & 75.0 & 1.3 \\
\hline November & $49 \pm 0.6$ & $59.8^{\mathrm{b}}$ & $52.2^{\mathrm{c}}$ & $82.4^{\mathrm{a}}$ & $82.5^{\mathrm{a}}$ & $42.3^{\mathrm{d}}$ & $81.7^{\mathrm{a}}$ & 68.4 & 1.4 \\
\hline December & $53 \pm 0.3$ & $62.9^{c}$ & $64.4^{\mathrm{c}}$ & $82.8^{b}$ & $90.1^{\mathrm{a}}$ & $45.8^{\mathrm{d}}$ & $85.7^{\mathrm{a}}$ & 73.3 & 1.4 \\
\hline January & $53 \pm 0.2$ & $63.5^{\mathrm{d}}$ & $71.9^{c}$ & $82.2^{\mathrm{b}}$ & $89.7^{\mathrm{a}}$ & $37.4^{\mathrm{e}}$ & $84.3^{\mathrm{b}}$ & 72.6 & 1.3 \\
\hline February & $53 \pm 0.3$ & $59.8^{\mathrm{c}}$ & $66.7^{\mathrm{c}}$ & $78.3^{\mathrm{b}}$ & $91.0^{\mathrm{a}}$ & $43.5^{\mathrm{d}}$ & $82.0^{\mathrm{b}}$ & 71.3 & 2.9 \\
\hline \multicolumn{10}{|c|}{ LowSD (north) ${ }^{11}$} \\
\hline May & $29 \pm 0.8$ & $27.8^{\mathrm{c}}$ & $13.4^{\mathrm{d}}$ & $36.4^{\mathrm{b}}$ & $43.3^{\mathrm{a}}$ & $9.8^{\mathrm{d}}$ & N/A & 27.4 & 1.6 \\
\hline June & $35 \pm 0.3$ & $27.1^{\mathrm{b}}$ & $18.6^{\mathrm{c}}$ & $58.9^{\mathrm{a}}$ & $57.0^{\mathrm{a}}$ & $12.5^{\mathrm{d}}$ & N/A & 36.7 & 1.5 \\
\hline July $^{9}$ & $31 \pm 0.7$ & $17.1^{\mathrm{d}}$ & $28.6^{\mathrm{c}}$ & $62.4^{\mathrm{a}}$ & $57.4^{\mathrm{b}}$ & $10.3^{\mathrm{e}}$ & N/A & 37.2 & 1.3 \\
\hline August & $34 \pm 0.5$ & $13.9^{\mathrm{c}}$ & $32.0^{\mathrm{b}}$ & $53.7^{\mathrm{a}}$ & $51.7^{\mathrm{a}}$ & $13.7^{\mathrm{c}}$ & N/A & 34.4 & 1.3 \\
\hline September ${ }^{10}$ & $32 \pm 0.4$ & $14.4^{\mathrm{c}}$ & $36.6^{\mathrm{b}}$ & $58.5^{\mathrm{a}}$ & $58.2^{\mathrm{a}}$ & $10.0^{\mathrm{d}}$ & N/A & 37.5 & 1.3 \\
\hline October & $36 \pm 0.8$ & $24.0^{\mathrm{d}}$ & $39.9^{\mathrm{c}}$ & $57.3^{\mathrm{b}}$ & $68.3^{\mathrm{a}}$ & $20.7^{\mathrm{d}}$ & N/A & 43.6 & 1.3 \\
\hline November & $38 \pm 0.6$ & $14.7^{\mathrm{e}}$ & $39.3^{\mathrm{c}}$ & $50.6^{\mathrm{b}}$ & $64.1^{\mathrm{a}}$ & $18.4^{\mathrm{d}}$ & N/A & 38.9 & 1.3 \\
\hline December & $35 \pm 0.7$ & $18.8^{\mathrm{e}}$ & $34.8^{\mathrm{c}}$ & $52.9^{b}$ & $59.1^{\mathrm{a}}$ & $23.6^{\mathrm{d}}$ & N/A & 38.9 & 1.4 \\
\hline January & $38 \pm 0.8$ & $19.1^{\mathrm{e}}$ & $39.5^{\mathrm{c}}$ & $57.3^{\mathrm{b}}$ & $66.8^{\mathrm{a}}$ & $23.0^{\mathrm{d}}$ & N/A & 42.5 & 1.3 \\
\hline February & $39 \pm 0.0$ & $19.5^{\mathrm{b}}$ & $63.7^{\mathrm{a}}$ & $64.0^{\mathrm{a}}$ & $71.4^{\mathrm{a}}$ & $19.1^{\mathrm{b}}$ & N/A & 49.5 & 2.7 \\
\hline
\end{tabular}

a,b,c,d,e,f Percentages within rows with different superscripts differ $(P<0.05)$.

${ }^{1}$ Percentage $=$ Number of stall-day-occupied observations / Total number stall-day observations by stall base for each month by side.

${ }^{2}$ Occupied is defined as Lying + Standing + Half-in-and-out.

${ }^{3}$ Stall bases: rubber mat $=$ Comfort Zone-Milk Mat, waterbed = Atlanta Cow Waterbeds, MATR2 = Comfy Cow Free Stall Mattress, MATR1 $=$ Pasture Mat Mattresses, concrete $=$ concrete, and sand $=$ sand stalls.

${ }^{4}$ Data collected from May 9, 2001 to February 9, 2002.

${ }^{5}$ Mean ( \pm SE) number of cows for the south side (parlor) during each month.

${ }^{6}$ Mean percentage occupied equals Total stall-day-occupied observations/Total number stall-day observations for each month by side.

${ }^{7}$ S.E. refers to the pooled standard error for each month by side.

${ }^{8} 100 \%$ SD (south) refers to the south side of the freestall barn with $100 \%$ stocking density.

${ }^{9}$ Rubber mat were refastened to the respective stalls.

${ }^{10}$ Waterbed were adjusted by adding additional water and replacing clamps.

${ }^{11}$ LowSD (north) refers to the north side of the freestall barn with low stocking density.

ture 81 to $100^{\circ} \mathrm{F}\left(27.2\right.$ to $\left.37.8^{\circ} \mathrm{C}\right)$. Mean percentage lying, across all stall bases, was low during warm temperature 81 to $100^{\circ} \mathrm{F}\left(27.2\right.$ to $\left.37.8^{\circ} \mathrm{C}\right)$. Some form of heat abatement may be needed in the facility during warm weather. Future research should be conducted to determine how the use of fans and sprinklers affects stall use.

Figure 5 shows the percentage of stalls with cows lying on the LowSD side for stall base by temperature $\left({ }^{\circ} \mathrm{F}\right)$ interval, which had similar results; however, MATR2 had a slightly higher lying percentage (25.4\%) during warm temperature than MATR1 (22.8\%).

Figure 6 shows the percentage of stalls occupied on the $100 \% \mathrm{SD}$ side for stall base by temperature $\left({ }^{\circ} \mathrm{F}\right)$ interval. Results for stall occupied percentages on 100\%SD show MATR1 (97.4 to $78.1 \%$ ) were the highest $(P<0.05)$ across all temperature intervals. The MATR2 based stalls ( 70.8 to $87.1 \%$ ) and sand (55.6 to $89.0 \%$ ) followed with MATR2 preferred during temperature 41 to $100^{\circ} \mathrm{F}\left(5.0\right.$ to $\left.37.8^{\circ} \mathrm{C}\right)$. Cows preferred rubber mat to waterbed during mild to warm temperature, 41 to $80^{\circ} \mathrm{F}$ (5.0 to $26.7^{\circ} \mathrm{C}$ ). Mean percentage occupied was high (78.2\%) during cold temperature 1 to $20^{\circ} \mathrm{F}$ ( -17.2 to $-6.7^{\circ} \mathrm{C}$ ) and low $(54.3 \%)$ during warm temperature 81 to $100^{\circ} \mathrm{F}\left(27.2\right.$ to $\left.37.8^{\circ} \mathrm{C}\right)$.

Figure 7 shows the percentage of stalls occupied on the LowSD side for stall base by temperature $\left({ }^{\circ} \mathrm{F}\right)$ interval, which showed similar trends; however, MATR2 $(47.0 \%)$ had a higher $(P<0.05)$ stall occupied percentage than MATR1 (35.1\%) during warm temperature 81 to $100^{\circ} \mathrm{F}\left(27.2\right.$ to $\left.37.8^{\circ} \mathrm{C}\right)$ and was similar to MATR 1 during cold temperature 1 to $20^{\circ} \mathrm{F}\left(-17.2\right.$ to $\left.-6.7^{\circ} \mathrm{C}\right)$. The waterbed based stalls were higher $(P<0.05)$ than rubber mat across all temperature intervals. Concrete was lower during cold temperature 1 to $20^{\circ} \mathrm{F}$ ( -17.2 to $-6.7^{\circ} \mathrm{C}$ ) and during mild to warm temperature 41 to $100^{\circ} \mathrm{F}\left(5.0\right.$ to $\left.37.8^{\circ} \mathrm{C}\right)$. Cows may prefer a cushioned stall base with a cooler surface during warm temperature.

The lying and stall-occupied results for sand differed from Thoreson et al. (2000), who found sand was used 


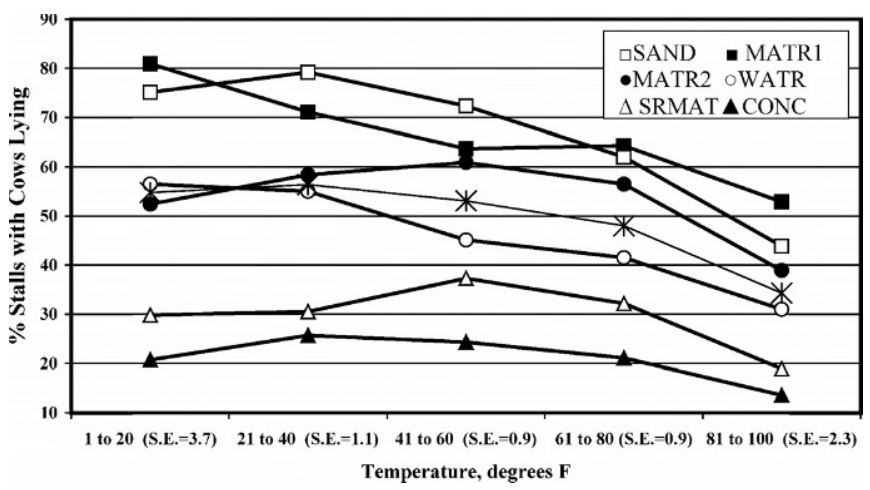

Figure 4. Percentage of stalls with cows lying on $100 \%$ SD side, for each stall base type, by temperature interval. Percentage lying = number of stall-day-lying observations / total stall-day observations by stall base. Stall base's $=($ rubber mat $($ empty triangle $)=$ Comfort Zone-Milk Mat, waterbed (empty circle) = Atlanta Cow Waterbeds, MATR2 $($ filled circle) $=$ Comfy Cow Free Stall Mattress, MATR1 (filled square $)=$ Pasture Mat Mattresses, concrete (filled triangle $)=$ concrete, and sand (empty square) $=$ sand stalls). Temperature interval $=$ temperature interval $\left({ }^{\circ} \mathrm{F}\right) .100 \% \mathrm{SD}=$ side of the freestall barn with $100 \%$ stocking density. Mean percentage lying across all stall bases is represented by (*). All stall bases were different $(P<0.05)$ for 41 to $60^{\circ} \mathrm{F}\left(5.0\right.$ to $\left.15.6^{\circ} \mathrm{C}\right)$. S.E. is each temperature interval's pooled standard error.

less during winter compared to summer. Thoreson et al. (2000) also found sand occupancy percentage (60.8\%) during a summer trial was higher than mattresses (19.4 to $32.5 \%)$ and rubber mats (12.3\%). Differences may be attributed to other seasonal factors such as relative humidity, which was not available for the current

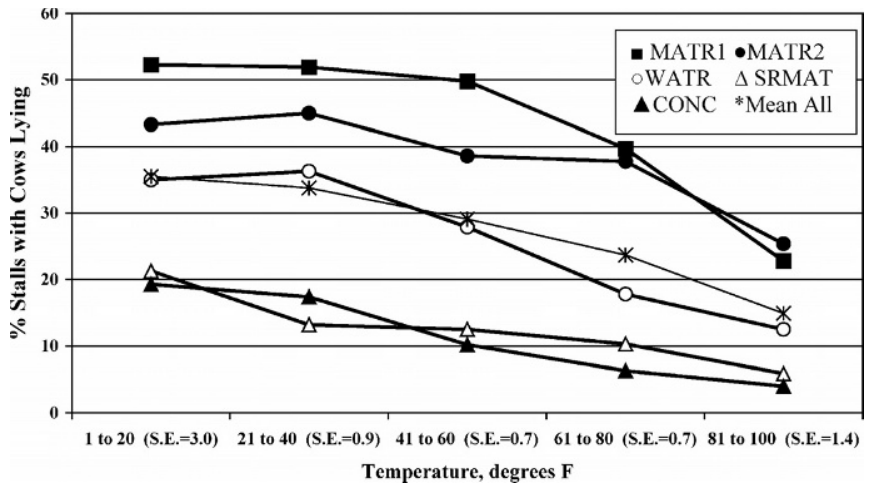

Figure 5. Percentage of stalls with cows lying on LowSD side, for each stall base type, by temperature interval. Percentage lying = number of stall-day-lying observations / total stall-day observations by stall base. Stall base's $=($ rubber mat $($ empty triangle $)=$ Comfort Zone-Milk Mat, waterbed (empty circle $)=$ Atlanta Cow Waterbeds, MATR2 (filled circle) $=$ Comfy Cow Free Stall Mattress, MATR1 (filled square $)=$ Pasture Mat Mattresses, and concrete (filled triangle) $=$ concrete). Temperature interval $=$ temperature interval $\left({ }^{\circ} \mathrm{F}\right)$. LowSD $=$ side of the freestall barn with low (66\%) stocking density. Mean percentage lying across all stall bases is represented by $\left(^{*}\right)$. All stall bases were different $(P<0.05)$ for 21 to $60^{\circ} \mathrm{F}\left(-6.1\right.$ to $\left.15.6^{\circ} \mathrm{C}\right)$. S.E. is each temperature interval's pooled standard error.

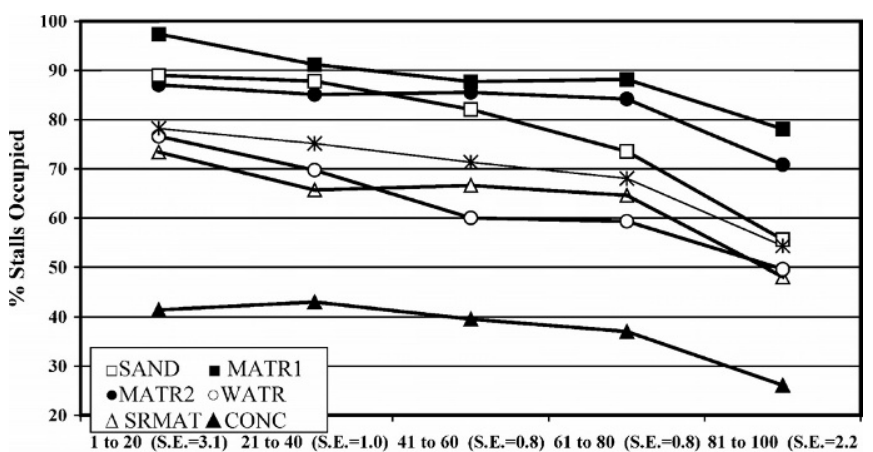

Temperature, degrees $\mathbf{F}$

Figure 6. Percentage of stalls occupied on $100 \%$ SD side, for each stall base type, by temperature interval. Occupied = Lying + Standing + Half-in-and-out. Percentage occupied $=$ number of stall-day-occupied observations / total stall-day observations by stall base. Stall base's $=($ rubber mat $($ empty triangle $)=$ Comfort Zone-Milk Mat, waterbed $($ empty circle $)=$ Atlanta Cow Waterbeds, MATR2 $($ filled circle $)=$ Comfy Cow Free Stall Mattress, MATR1 (filled square) $=$ Pasture Mat Mattresses, concrete (filled triangle) $=$ concrete, and sand (empty square $)=$ sand stalls $)$. Temperature interval $=$ temperature interval $\left({ }^{\circ} \mathrm{F}\right) .100 \% \mathrm{SD}=$ side of the freestall barn with $100 \%$ stocking density. Mean percentage occupied across all stall bases is represented by $(*)$. All stall bases were different $(P<0.05)$ for 21 to $80^{\circ} \mathrm{F}$ $\left(-6.1\right.$ to $\left.26.7^{\circ} \mathrm{C}\right)$. S.E. is each temperature interval's pooled standard error.

study's analysis. The level of sand based stalls or sand quality may have also contributed to the difference. Results for rubber mat and concrete were similar to

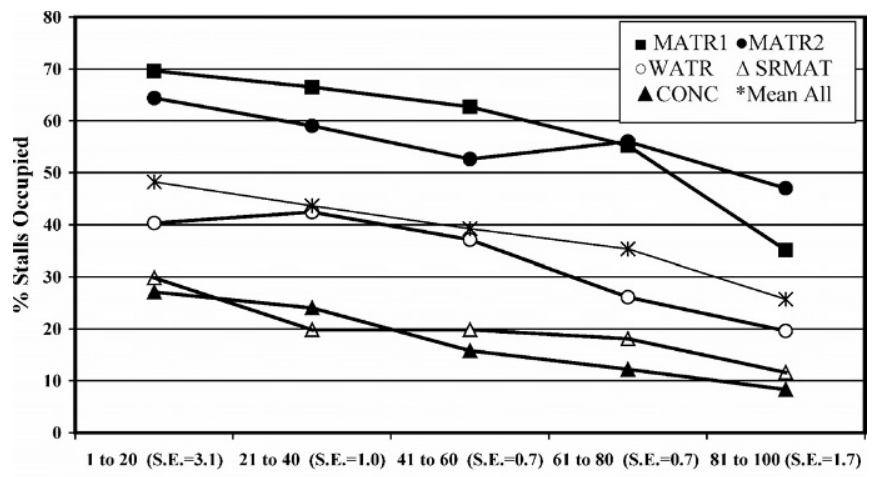

Temperature, degrees $\mathrm{F}$

Figure 7. Percentage of stalls occupied on LowSD side, for each stall base type, by temperature interval. Occupied = Lying + Standing + Half-in-and-out. Percentage occupied $=$ number of stall-day-occupied observations / total stall-day observations by stall base. Stall base's $=$ (rubber mat (empty triangle $)=$ Comfort Zone-Milk Mat, waterbed $($ empty circle $)=$ Atlanta Cow Waterbeds, MATR2 $($ filled circle $)=$ Comfy Cow Free Stall Mattress, MATR1 (filled square) $=$ Pasture Mat Mattresses, and concrete(filled triangle) = concrete). temperature interval $=$ temperature interval $\left({ }^{\circ} \mathrm{F}\right)$. LowSD $=$ side of the freestall barn with Low (66\%) stocking density. Mean percentage occupied across all stall bases is represented by (*). All stall bases were different $(P<0.05)$ for 21 to $60^{\circ} \mathrm{F}\left(-6.1\right.$ to $\left.15.6^{\circ} \mathrm{C}\right)$. S.E. is each temperature interval's pooled standard error. 
Table 5. Stall occupancy percentages ${ }^{1}( \pm \mathrm{SE})$ by $\mathrm{WDIST}^{2}$ for each side. ${ }^{3}$

\begin{tabular}{|c|c|c|c|c|c|}
\hline & (1 to 4$)$ & (5 to 8$)$ & (9 to 12$)$ & (13 to 17$)$ & (17 to 20$)$ \\
\hline \multicolumn{6}{|l|}{$100 \%$ SD (south) 4} \\
\hline Empty & $28.7^{\mathrm{b}} \pm 0.5$ & $29.9^{\mathrm{b}} \pm 0.4$ & $35.8^{\mathrm{a}} \pm 0.4$ & $18.3^{\mathrm{c}} \pm 0.4$ & \\
\hline Half-in-and-out & $7.7^{\mathrm{a}} \pm 0.3$ & $7.2^{\mathrm{a}} \pm 0.2$ & $7.0^{\mathrm{a}} \pm 0.2$ & $5.6^{\mathrm{b}} \pm 0.2$ & \\
\hline Lying & $50.5^{\mathrm{b}} \pm 0.5$ & $51.4^{\mathrm{b}} \pm 0.4$ & $47.4^{\mathrm{c}} \pm 0.4$ & $57.0^{\mathrm{a}} \pm 0.5$ & \\
\hline Standing & $12.3^{\mathrm{b}} \pm 0.3$ & $10.7^{\mathrm{c}} \pm 0.2$ & $9.6^{\mathrm{d}} \pm 0.2$ & $18.9^{\mathrm{a}} \pm 0.4$ & \\
\hline Occupied $^{5}$ & $70.4^{\mathrm{b}} \pm 0.5$ & $69.4^{\mathrm{b}} \pm 0.4$ & $64.0^{\mathrm{c}} \pm 0.4$ & $81.5^{\mathrm{a}} \pm 0.4$ & \\
\hline Unsure & $0.9^{\mathrm{a}} \pm 0.1$ & $0.8^{\mathrm{a}} \pm 0.1$ & $0.2^{b} \pm 0.0$ & $0.2^{b} \pm 0.0$ & \\
\hline Total number 6 & 9610 & 15,376 & 14,415 & 8649 & \\
\hline \multicolumn{6}{|l|}{ LowSD (north) ${ }^{7}$} \\
\hline Empty & $47.6^{\mathrm{d}} \pm 0.6$ & $66.5^{\mathrm{b}} \pm 0.4$ & $75.6^{\mathrm{a}} \pm 0.4$ & $59.3^{\mathrm{c}} \pm 0.6$ & $40.5^{\mathrm{e}} \pm 0.6$ \\
\hline Half-in-and-out & $4.4^{\mathrm{a}} \pm 0.2$ & $4.0^{\mathrm{a}} \pm 0.2$ & $2.9^{\mathrm{bc}} \pm 0.1$ & $2.5^{\mathrm{c}} \pm 0.2$ & $3.2^{\mathrm{b}} \pm 0.2$ \\
\hline Lying & $38.2^{\mathrm{b}} \pm 0.5$ & $24.1^{\mathrm{d}} \pm 0.4$ & $16.9^{\mathrm{e}} \pm 0.3$ & $28.3^{c} \pm 0.5$ & $43.9^{\mathrm{a}} \pm 0.6$ \\
\hline Standing & $9.7^{\mathrm{b}} \pm 0.3$ & $4.6^{\mathrm{c}} \pm 0.2$ & $4.5^{\mathrm{c}} \pm 0.2$ & $9.9^{\mathrm{b}} \pm 0.3$ & $12.3^{\mathrm{a}} \pm 0.4$ \\
\hline Occupied $^{5}$ & $52.2^{\mathrm{b}} \pm 0.6$ & $32.7^{\mathrm{d}} \pm 0.4$ & $24.3^{\mathrm{e}} \pm 0.4$ & $40.7^{\mathrm{c}} \pm 0.6$ & $59.5^{\mathrm{a}} \pm 0.6$ \\
\hline Unsure & $0.2^{\mathrm{b}} \pm 0.1$ & $0.8^{\mathrm{a}} \pm 0.1$ & $0.1^{\mathrm{c}} \pm 0.0$ & $0.0^{\mathrm{d}} \pm 0.0$ & $0.0^{\mathrm{d}} \pm 0.0$ \\
\hline Total number 6 & 7863 & 12,046 & 14,744 & 7864 & 6881 \\
\hline
\end{tabular}

a,b,c,dPercentages within rows with different superscripts differ $(P<0.05)$.

${ }^{1}$ Percentage $=$ Number of stall-day-status observations / Total number of stall-day observations by stall distance to water by side.

${ }^{2}$ Stall distance to water is measured in units, 1 unit is approximately equal to 1 stall width, and summarized as intervals.

${ }^{3}$ Data collected from May 9, 2001 to February 9, 2002.

${ }^{4} 100 \% \mathrm{SD}$ (south) refers to the south side of the freestall barn with $100 \%$ stocking density.

${ }^{5}$ Occupied is defined as Lying + Standing + Half-in-and-out.

${ }^{6}$ Total number is equal to Total number of stall-day observations by stall distance to water by side.

${ }^{7}$ LowSD (north) refers to the north side of the freestall barn with low stocking density.

previous research. Rubber mats were chosen over concrete during summer and winter trials (Gebremedhin et al., 1981).

Stall use percentages by WDIST showed that cows preferred stalls the closest to and farthest from water (Table 5). This confusing result can be explained by the significant WDIST $\times$ stall base interaction. Sand and MATR1 based stalls were preferred by cows and the $100 \%$ SD side had sand based stalls the closest and MATR1 based stalls the farthest from water. Results from the LowSD side showed a similar trend and corresponds to the location of the MATR1 type stalls.

Table 6 shows percentage of stalls with cows lying and stalls occupied for interior and exterior rows by time for each side. Lying and occupied percentages differed by time of day. Cows preferred lying in stalls on the exterior row at time 8 p.m., 4 a.m., and 9 a.m. and preferred to occupy stalls on the exterior row for all time. The highest percentage of cows lying and stalls occupied during the early morning was at 4 a.m. A lower percentage of cows were lying (38.6\%) and occupying $(59.4 \%)$ stalls during the afternoon at 2 p.m. This was slightly higher than $30.1 \%$ lying and $49.7 \%$ occupied for a 4 to $6 \mathrm{~h}$ afternoon observation from a previous study reviewed by Rodenburg and House (2000). Increased hours of observation for the previous study may have contributed to the difference. Time of day should be considered when selecting a time to evaluate stall usage in existing facilities as a measure of cow preference and comfort. Higher lying and occupancy percentages at 4 a.m. suggest an early morning stall use observation would be beneficial in evaluating cow comfort on a dairy.

Smaller lying and stall occupied percentages on the LowSD were attributed to the lower stocking density. Observation time points may have favored the schedule of cows housed on $100 \%$ SD because observation times were selected based on their milking schedule. Cows on LowSD experienced different cow movement controls, such as one-way gates and a more relaxed milking schedule with the robot.

An analysis of only Wednesday observation data was done to determine if one-day-a-week observation of stall occupancy was sufficient in categorizing stall use versus observing every day for a 9-mo period. Results were similar to those found in Table 1 with some loss in significant differences between stall bases due to fewer observations. It was determined that one-day-a-week analysis would be adequate in determining stall occupancy as a measure of cow preference and comfort.

\section{CONCLUSIONS}

This study shows that stall base type affects cow preference. Sand and MATR1 based stalls consistently had larger stall use percentages, whereas concrete and 
Table 6. Percentage ${ }^{1}$ of stalls with cows lying and stalls occupied ${ }^{2}$ for interior and exterior row ${ }^{3}$ by time of day or each side. ${ }^{4}$

\begin{tabular}{|c|c|c|c|c|c|c|c|c|}
\hline & \multicolumn{4}{|c|}{ Lying } & \multicolumn{4}{|c|}{ Occupied } \\
\hline & interior & exterior & $\bar{x}^{5}$ & S.E. ${ }^{6}$ & interior & exterior & $\bar{x}^{7}$ & S.E. ${ }^{8}$ \\
\hline \multicolumn{9}{|c|}{$100 \%$ SD (south) ${ }^{9}$} \\
\hline 2 p.m. & $38.6^{\mathrm{a}}$ & $38.7^{\mathrm{a}}$ & 38.6 & 0.6 & $58.1^{b}$ & $60.5^{\mathrm{a}}$ & 59.4 & 0.6 \\
\hline 8 p.m. & $47.1^{\mathrm{b}}$ & $53.8^{\mathrm{a}}$ & 50.7 & 0.6 & $63.3^{\mathrm{b}}$ & $75.2^{\mathrm{a}}$ & 69.7 & 0.5 \\
\hline 4 a.m. & $56.7^{\mathrm{b}}$ & $61.0^{\mathrm{a}}$ & 59.0 & 0.7 & $78.0^{\mathrm{b}}$ & $85.0^{\mathrm{a}}$ & 81.8 & 0.5 \\
\hline 9 a.m. & $53.9^{\mathrm{b}}$ & $58.6^{\mathrm{a}}$ & 56.4 & 0.7 & $67.4^{\mathrm{b}}$ & $74.4^{\mathrm{a}}$ & 71.2 & 0.5 \\
\hline \multicolumn{9}{|c|}{ LowSD (north) ${ }^{10}$} \\
\hline 2 p.m. & $19.6^{\mathrm{b}}$ & $24.2^{\mathrm{a}}$ & 22.1 & 0.5 & $30.9^{\mathrm{b}}$ & $36.2^{\mathrm{a}}$ & 33.8 & 0.6 \\
\hline 8 p.m. & $19.1^{\mathrm{b}}$ & $22.7^{\mathrm{a}}$ & 21.0 & 0.5 & $27.0^{\mathrm{b}}$ & $35.3^{\mathrm{a}}$ & 31.5 & 0.6 \\
\hline 4 a.m. & $39.4^{\mathrm{b}}$ & $47.8^{\mathrm{a}}$ & 43.9 & 0.7 & $49.5^{\mathrm{b}}$ & $60.9^{\mathrm{a}}$ & 55.6 & 0.6 \\
\hline 9 a.m. & $23.1^{\mathrm{b}}$ & $28.6^{\mathrm{a}}$ & 26.1 & 0.5 & $31.1^{\mathrm{b}}$ & $38.6^{\mathrm{a}}$ & 35.1 & 0.6 \\
\hline \multicolumn{9}{|c|}{$\begin{array}{l}\text { a,b Percentages within rows, lying and occupied analyzed separately, with different superscripts differ }(P \\
0.05) \text {. }\end{array}$} \\
\hline \multicolumn{9}{|c|}{$\begin{array}{l}{ }^{1} \text { Percentage }=\text { Number of stall-day-lying (occupied) observations / Total number stall-day observations by } \\
\text { row for each time by side. }\end{array}$} \\
\hline \multicolumn{9}{|l|}{00} \\
\hline \multicolumn{9}{|c|}{${ }^{3}$ Rows: interior $=$ interior row and exterior $=$ exterior row. } \\
\hline \multicolumn{9}{|c|}{${ }^{4}$ Data collected from May 9, 2001 to February 9, 2002.} \\
\hline \multicolumn{9}{|c|}{$\begin{array}{l}{ }^{5} \text { Mean percentage lying equals Total stall-day-lying observations / Total number stall-day observations } \\
\text { for each time by side. }\end{array}$} \\
\hline \multicolumn{9}{|c|}{${ }^{6}$ S.E. refers to the pooled standard error for lying by time. } \\
\hline \multicolumn{9}{|c|}{$\begin{array}{l}{ }^{7} \text { Mean percentage occupied equals Total stall-day-occupied observations/Total number stall-day observa- } \\
\text { tions for each time by side. }\end{array}$} \\
\hline \multicolumn{9}{|c|}{${ }^{8}$ S.E. refers to the pooled standard error for occupied by time. } \\
\hline \multicolumn{9}{|c|}{${ }^{9} 100 \% \mathrm{SD}$ (south) refers to the south side of the freestall barn with $100 \%$ stocking density. } \\
\hline
\end{tabular}

rubber mat were consistently the lowest percentages, and MATR2 and waterbed percentages were intermediate. The sand-based stalls had the highest overall lying percentage, but MATR1 and MATR2 had the highest stall occupied percentages. Cows appear to prefer to stand on soft surfaces provided by mattresses or rubber mats to sand stalls or concrete alleys. The lying percentage advantage of sand over MATR1 $(68.7 \%>65.2 \%)$ was small compared to the stall occupied advantage of MATR1 over sand $(88.3 \%>79.0 \%)$. This suggests cows like to lie down on both stall bases, but prefer to spend non-lying time standing in MATR1 based stalls rather than on concrete manure alleys. It also suggests that evaluating stall usage only on the ratio of stalls with cows standing to stalls occupied may be misleading since it does not consider the occupancy rate of the stalls. On the other hand, rubber mat had a very high percentage standing $(24.6 \%)$ and a low percentage lying (32.9\%), which supports some people's concern that excess standing may indicate the stall surface is uncomfortable to lie on.

Some stall base types were consistently inferior to others. Lying percentages for concrete and rubber mat were always below the average lying percentages. MATR1 based stalls consistently ranked higher than MATR2 for lying and stall occupied percentages, which indicates not all mattresses are equally desirable to cows and making general statements about "mattresses" may be misleading.

The length of time cows are exposed to stall bases affects lying and occupied percentages. The waterbed based stalls required a longer adaptation time whereas use of rubber mat based stalls decreased over time. Cows preferred the exterior row on both sides. Cows may prefer to lie in and occupy stalls near better-ventilated areas. The NOTEND stalls were used more than END stalls. Along with the stall base $\times$ STLLOC interaction, this suggests there was something different about the END stalls that affected cow preference. The results of this study yielded conflicting and confusing results about the effect of distance-to-water on stall usage. WDIST was a significant predictor of stall use, but the analysis suggested cows preferred stalls closest to and farthest from water. The significant stall base $\times$ WDIST interaction suggests the results to be an artifact of the random selecting of locations.

Temperature appears to affect cows' preference for a particular stall base. Lying percentages were higher for MATR1 stalls during hot and cold temperatures, but were higher for sand during moderate temperature conditions. Mattresses may provide insulation from the concrete during cold temperatures while sand may be 
too cold. As stocking density increased, cow position percentages (lying and stall occupied) increased, suggesting stocking density should be considered when evaluating stall usage. The percentage of stalls with cows lying or were occupied was higher in the morning than the afternoon or night and the highest levels were observed in the early morning before milking and feeding activity began.

Based on the results of this study, the following guidelines are suggested when evaluating the cow comfort of stalls in a freestall barn: If possible, observe the stall occupancy early in the morning before feeding or milking activity has begun. Count the number of stalls with a cow lying and stalls occupied. If the barn has a $100 \%$ stocking rate, then a 55 to $65 \%$ lying percentage and an 80 to $85 \%$ occupancy percentage would be considered very good. As stocking rate changes, expect these percentages to change about proportionately to the stocking rate. If observations are taken later in the day, expect these values to drop by 10 to 20 percentage points.

Further research would lead to a better understanding of how stall location affects cow preference for different stall bases. The interaction with other factors, such as stall base, temperature, or WDIST should be investigated further. Percentage of cows lying and occupying stalls, time of day, temperature, and stocking density should be considered in the development and testing of an alternative index to measure the relative cow comfort of different stall bases.

\section{ACKNOWLEDGMENTS}

The authors would like to thank the employees of the Blaine Dairy, Arlington research facility, for their assistance in switching tapes and monitoring camera function, and Brian Holmes for assistance in setting up the project. The authors also thank Doug Hemken, Social Science Microcomputer Laboratory, Yu-mei Chang, Department of Animal Sciences, and Jun Zhu, Department of Statistics, for their assistance in the statistical analysis of the data. A special thank you to Dr. Randy Shaver for his comments and assistance reviewing the write-up. Funding for this research and publication from the USDA Cooperative State Research, Education and Extension Service (CSREES) project WIS01892.

\section{REFERENCES}

Albright, L. D., and M. B. Timmons. 1984. Behavior of dairy cattle in free stall housing. Trans. ASAE. 27(4):1119-1126.
Bickert, W. G., and R. W. Ashley. 1991. Free stall design and management: Michigan experiences. Paper \# 914566. Am. Soc. Agric. Eng., December Chicago, IL.

Chaplin, S. J., G. Tierney, C. Stockwell, D. N. Logue, and M. Kelly. 2000. An evaluation of mattresses and mats in two dairy units. Appl. Anim. Behaviour Sci. 66:263-272.

Cook, N. B. 2002. Lameness prevalence and the effect of housing on 30 Wisconsin dairy herds. Pages $325-327$ in Proc. 12th Intl. Lameness Ruminants Symp. Orlando, Florida.

Feddes, J., B. Robinson, and R. Borg. 1995. Building for cow comfort. http://www.afns.ualberta.ca/wcds/wed95067.htm.

Gebremedhin, K. G., C. O. Cramer, and H. J. Larsen. 1981. Behavioral responses of dairy cows in selection of stalls in confinement. Paper \# 81-4542. Am. Soc. Agric. Eng., December Chicago, IL.

Haley, D. B., J. Rushen, and A. M. de Passillé. 1999. Behavioural indicators of cow comfort: activity and resting behaviour of dairy cows in two types of housing. Can. J. Anim. Sci. 80:257-263.

Hemken, D. 2002. Personal Communication.

Herlin, A. H. 1997. Comparison of lying area surfaces for dairy cows by preference, hygiene and lying down behaviour. Swed. J. Agric. Res. 27:189-196.

House, H. K. 1998. Rubber filled cow mattress update. Pages 177183 in Proc. 4th Intl. Dairy Housing Conf.

House, H. K., N. G. Anderson, and J. Rodenburg. 1994. Recent developments of the cow mattress in Ontario. Pages 303-312 in Ann. Mtg. Natl. Mastitis Counc., Inc. Arlington, VA.

Krohn, C. C., and L. Munksgaard. 1993. Behavior of dairy cows kept in extensive (loose housing/pasture) or intensive (tie stall) environments. II. Lying and lying-down behavior. Appl. Anim. Behaviour Sci. 37:1-16.

Leonard, F. C., and J. M. O'Connell. 1997. Cubicle housing conditions and cow comfort. Irish Vet. J. 50:675-682.

Muller, C. J. C. and J. A. Botha. 1997. Cow behavior in relation to different freestall surfaces during winter in a temperate climate. Pages 1069-1076 in Livestock Environ. 5, Vol. 2. Am. Soc. Agric. Eng., St. Joseph, Michigan.

Natzke, R. P., D. R. Bray, and R. W. Everett. 1982. Cow preference for free stall surface material. J. Dairy. Sci. 65:146-153.

Overton, M. W., W. M. Sischo, G. DeChant, and D. A. Moore. 2000. Observations of dairy cattle behavior using time-lapse photography in a California free-stall barn. Pages 138-139 in Proc. Ann. Conf. Am. Assoc. Bovine Pract. 33rd Conf. Stillwater, OK.

Rodenburg, J. and H. K. House. 2000. The impact of freestall base and bedding on cow comfort. Pages 214-225 in Dairy Housing and Equipment Systems Managing and Planning for profitability. NRAES-129.

Rodenburg, J., H. K. House, and N. G. Anderson. 1994. Free stall base and bedding materials: effect on cow comfort. Pages in 286291 Ann. Mtg. Natl Mastitis Counc. Inc. Arlington, VA.

SAS: User's Guide: Statistics. 1999. Version 5 Edition. SAS Institute, Cary, NC.

Sonck, B., and J. Daelemans. 1999. Comparison of free stall cattle mattresses in a preference test. Proc. 50th Ann. Mtg Euro. Assoc. Animal Prod. Zurich, Switzerland.

Stokes, M. E., C. S. Davis and G. G. Koch. 1995. Using the GENMOD procedure. Pages 208-212 in Categorical Data Analysis Using the SAS System.

Thoreson, D. R., D. C. Lay, and L. L. Timms. 2000. Dairy free stall preference field study. 2000 Dairy Report - Iowa State University.

Tucker, C. B. and D. M. Weary. 2001. Cow comfort and free-stall design. Pages 76-91 in Leading Edge 2001. Ontario Dairy Symp.

Visser, R. Q. 1994. A comparison of bedding material for dairy cows. Pages 186-191 in Dairy Systems for the 21st Century. Proc. 3rd Intl. Dairy Housing Conf. Orlando, FL. 